\title{
Energy Based Virtual Damping Control of FB- MMCs for HVDC Grid
}

\author{
Ding Zhou, Rui Li, Member, IEEE Lie Xu, Senior Member, IEEE and Yi Wang, Member, IEEE
}

\begin{abstract}
Full-bridge submodule based modular multilevel converters (FB-MMCs) have attracted wide attention due to the DC fault blocking capability. However, the blocking of the FBMMC can only suppress its DC terminal current while the fault currents may still circulate along the meshed DC network. To address this issue, an energy based virtual damping control is proposed, where the DC terminal current of the FB-MMC is regulated to follow the DC voltage in the event of a DC fault. The FB-MMC is thus controlled as a virtual damping resistor to actively absorb the residual energy in the DC network and quickly suppress the potential circulating DC fault currents. This enables fast fault isolation using DC switches and thereby fast fault recovery after fault isolation. The fault isolation time is significantly reduced from around $120 \mathrm{~ms}$ with the FB-MMC simply being blocked and $50 \mathrm{~ms}$ with the conventional FB-MMC fault control method to around $15 \mathrm{~ms}$. The validity of the proposed control is verified in a three-terminal meshed DC network.
\end{abstract}

Index Terms-DC fault protection, full-bridge, HVDC grid, modular multilevel converter (MMC), virtual damping control.

\section{INTRODUCTION}

$\mathrm{H}$ igh-voltage DC (HVDC) transmission systems based on modular multilevel converters (MMCs) have developed rapidly due to their significant advantages. However, the behaviors and characteristics of half-bridge (HB) submodule (SM) based MMC (HB-MMC) during DC faults are major issues to be considered in applications. In the event of a DC short circuit, high AC current flowing through the freewheeling diodes of HB-MMC from the $\mathrm{AC}$ to the $\mathrm{DC}$ side, requires additional measures and could potentially cause serious damage to the converters and associated semiconductor devices [1-3].

Due to the DC fault blocking capability, full-bridge (FB) SM based MMCs (FB-MMCs) have attracted much attention. By blocking all the semiconductor switches in the FB SM, the SM capacitor voltage is inserted into the conduction path in

D. Zhou was with the Department of Electronic and Electrical Engineering, University of Strathclyde, Glasgow, G1 1XW, UK, and is now with the Global Energy Interconnection Research Institute Co., Ltd., Beijing, China (e-mail: zhouding2020@foxmail.com).

$\mathrm{R}$. $\mathrm{Li}$ and $\mathrm{L}$. Xu are with the Department of Electronic and Electrical Engineering, University of Strathclyde, Glasgow, G1 1XW, UK (e-mail: rui.li@strath.ac.uk, lie.xu@strath.ac.uk).

Y. Wang is with the State Key Laboratory of Alternate Electrical Power System with Renewable Energy Sources, North China Electric Power University, Baoding 071003, China (e-mail: yi.wang@ncepu.edu.cn). negative polarity to block the fault current flowing though the freewheeling diodes fed by the AC grid voltage [4, 5].

FB-MMC has been proposed for HVDC link with overhead lines, e.g. the ULTRANET direct current project $( \pm 380 \mathrm{kV}, 2$ GW, Germany), where DC faults could occur relatively frequently compared to schemes using cables. FB-MMC stations can quickly extinguish fault current and deionize the arc, and provide fast restart after clearance of temporary faults to minimize power transmission interruption [6].

By simply blocking the FB-MMCs, the fault currents can be quickly suppressed to zero in point-to-point HVDC links [4, 5]. This method is also applied in a three-terminal radial DC network in [7]. After DC fault currents are suppressed to around zero by blocking all the HVDC stations, the FB-MMCs are deblocked and operate as static synchronous compensators (STATCOMs) to provide reactive power to support the connected AC networks. The system recovery is then implemented after fault isolation by DC switches (DCS).

Active control of DC fault current is proposed in [8] to regulate the common-mode voltages by adjusting the output of the FB-MMC circulating current controller. The proposed control is disabled during normal operation but is activated after DC fault occurrence to effectively suppress the DC fault current to zero.

In $[9,10]$, the common-mode components of arm currents (i.e. half the sum of the upper and lower arm currents) are regulated by the SM capacitor voltage controller which also controls the DC current of the FB-MMC around zero during DC faults. An enhanced control is proposed in [11], to provide independent control of the positive and negative poles of a symmetrical monopole FB-MMC during asymmetrical DC faults, and to suppress the DC terminal current at zero during pole-to-pole DC faults.

Reference [12] proposes a voltage polarity reversal control of bipolar HVDC systems based on FB-MMCs. During DC faults, the DC voltage polarity is reversed to alleviate the current and voltage stresses of the FB-MMCs while maintaining the rated power transmission capability. The DC current is also reversed and is controlled at the rated value during DC faults. However, these active DC fault current control schemes have only been tested in simple point-to-point HVDC links and their validity in meshed DC grids remains unclear. 
In [13], the FB-MMC is switched to control its terminal DC current when fault occurs, and operates as a STATCOM. The terminal DC current control reference can be changed depending on different fault circumstances. However, the current reduction time of the DC network is found to be long due to oscillations and thus DC circuit breakers (DCCBs) are adopted, leading to high capital cost and losses.

In [14], the FB-MMC is used to control the DC fault current of the faulty line which is then isolated using solid-state switches based on IGBTs or IGCTs. The FB-MMCs are initially switched to control the DC terminal current and once the fault line is located, the MMCs on both terminals of the faulty line then regulate the DC current on the faulty cable to zero. This control can be implemented in a point-to-point HVDC system or a radial multi-terminal HVDC (MTDC) system. However, in a meshed MTDC system, the voltage change on the healthy cables caused by the current control of the faulty line will weaken the control performance and delay DC fault current interruption. This problem will be further discussed in this paper. In addition to the DC fault current of the faulty line, [15] further proposes to control the DC terminal current, DC terminal voltage and their combination to accelerate de-energization of the network during DC faults and concludes that the direct control of the DC fault current of the faulty line offers better performance compared to other alternatives. Thus, the direct line fault current control presented in [14] is described in detail in this paper for comparison to emphasize the advantages of the proposed control.

The aim of this paper is to use FB-MMCs to fast suppress the fault currents during DC faults to enable fault isolation using DCSs. The contributions of this paper are:

- A new energy based virtual damping control is proposed, where the DC terminal current of the FB-MMC is regulated to follow the DC voltage so the FB-MMC is acted as a virtual DC resistor during DC faults to actively absorb the residual energy in the meshed DC network to quickly suppress the potential circulating DC fault currents. This enables fast fault isolation using DC switches and thereby fast fault recovery after fault isolation.

- The operating mechanism of the proposed control is revealed from the energy perspective and the design principle of the virtual resistance is discussed.

The paper is organized as follows. In Section II, a threeterminal meshed HVDC system incorporating FB-MMCs is introduced. The fault characteristics of DC network is analyzed and the potential issues of conventional control are discussed in Section III. In Section IV, an energy based virtual damping control is proposed. The proposed control is assessed in Section $\mathrm{V}$ and finally, Section VI draws conclusions.

\section{SYSTEM LAYOUT}

The investigated three-terminal hybrid DC network is illustrated in Fig. 1, where the HB-MMC is adopted for Station 1 while the FB-MMC is used for Station 2 and 3. DCCBs are equipped at the DC terminals of the HB-MMC station for DC fault isolation, shown as DCCB 12 and 13 in Fig. 1. Considering the fault current controllability of the FB-MMC and to reduce the capital cost of protection equipment, DCSs are connected at the DC terminals of the FB-MMCs, shown as DCS 21, 23, 31, and 32. Station 1 controls the DC voltage of the DC network while Station 2 and 3 operate on active power control mode. All the three stations are modelled as MMC average-value model [16] with $320 \mathrm{HB}$ (Station 1) and $320 \mathrm{FB}$ (Stations 2 and 3) submodules per arm, respectively. The DCCB is represented as hybrid DCCB with fault current breaking time of $5 \mathrm{~ms}$ [17]. The DCS is modelled as SF6 puffer circuit breaker and can only open when its current is less than $100 \mathrm{~A}[14,15,18]$. Each DC transmission cable is represented by $10 \pi$-section transmission line models. The detailed parameters of the considered hybrid DC system are listed in Table I.

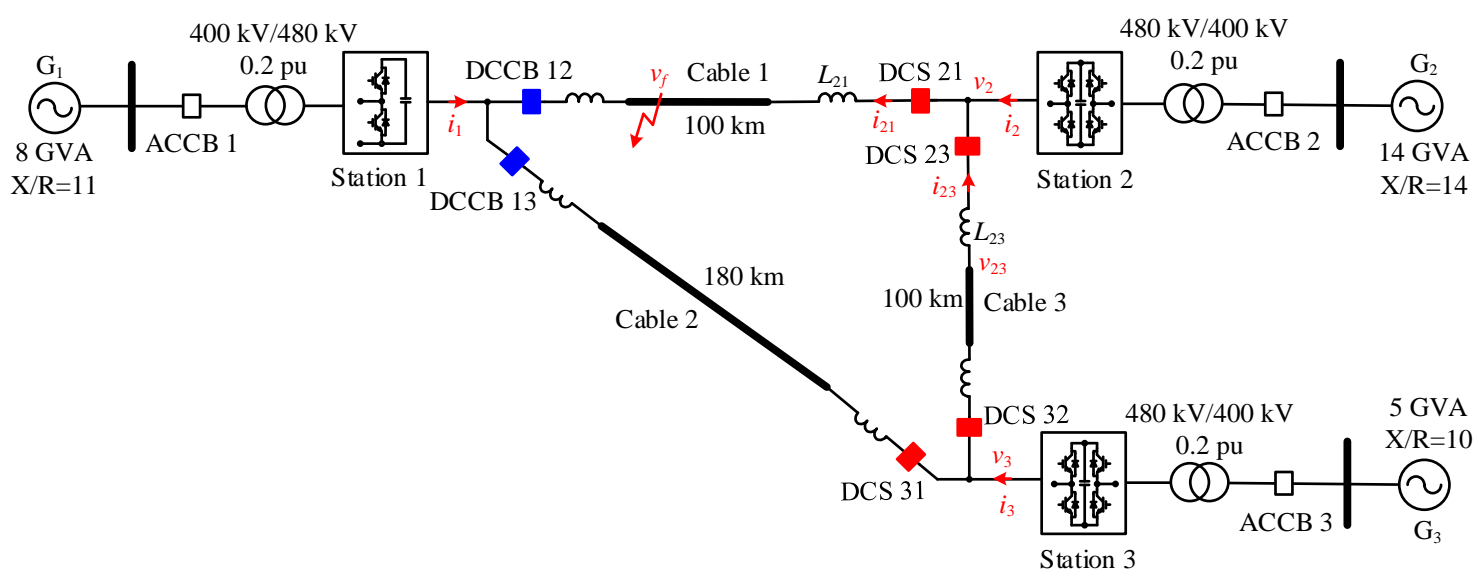

Fig. 1. Meshed hybrid DC network.

\section{FAUlT CHARACTERISTICS OF THE HYBRID DC NETWORK}

The fault characteristics of the investigated hybrid DC network are presented in this section, considering both the situations when the FB-MMCs are blocked and actively controlled, respectively.

\section{A. Fault Characteristics with FB-MMC Blocking}

FB-MMCs have DC fault blocking capability and thus, DCSs 
may be used for the protection of the DC network based on FBMMCs to reduce the cost of protection equipment. To isolate the fault, the currents flowing through DCSs need to be quickly suppressed to around zero, before opening the DCSs. For radial DC network where only one DC cable is connected at the terminal of the station as illustrated in Fig. 2, the DC fault currents $i_{2}$ and $i_{21}$ can be quickly suppressed to zero following the blocking of the FB-MMC and thus, DCS 21 can be fast opened at around zero current. However, for the considered meshed DC network, the fault currents exhibit different behaviors, as will be discussed in this subsection.

TABLE I

CONVERTER AND CABLE PARAMETERS

\begin{tabular}{l|c|l}
\hline \hline \multicolumn{1}{c|}{ Parameters } & Symbol & \multicolumn{1}{c}{ Nominal Value } \\
\hline Rated DC voltage & $V_{d c}$ & $\pm 400 \mathrm{kV}$ \\
\hline Power rating of Station 1 & $P_{1}$ & $2600 \mathrm{MW}$ \\
\hline Power rating of Station 2 & $P_{2}$ & $1300 \mathrm{MW}$ \\
\hline Power rating of Station 3 & $P_{3}$ & $1300 \mathrm{MW}$ \\
\hline $\begin{array}{l}\text { No. of SMs per arm for } \\
\text { Station 1, 2, }\end{array}$ & $N$ & 320 \\
\hline $\begin{array}{l}\text { SM capacitance for Station } \\
1,2,3\end{array}$ & $C_{s m}$ & $3.8 \mathrm{mF}, 1.9 \mathrm{mF}, 1.9 \mathrm{mF}$ \\
\hline Arm inductance & $L_{a r m}$ & $0.05 \mathrm{pu}$ \\
\hline Station 1 terminal inductance & $L_{1}$ & $100 \mathrm{mH}$ \\
\hline $\begin{array}{l}\text { Station 2 \& 3 terminal } \\
\text { inductance }\end{array}$ & $L_{2}$ & $30 \mathrm{mH}$ \\
\hline $\begin{array}{l}R, L \text { and } C \text { per unit length of } \\
\text { cable }\end{array}$ & $R_{\text {cable }}$ & $3 \mathrm{~m} \Omega / \mathrm{km}$ \\
\hline cable & $0.5 \mathrm{mH} / \mathrm{km}$ \\
\hline Number of $\pi$-sections & $C_{\text {cable }}$ & $0.2 \mu \mathrm{F} / \mathrm{km}$ \\
\hline \hline
\end{tabular}

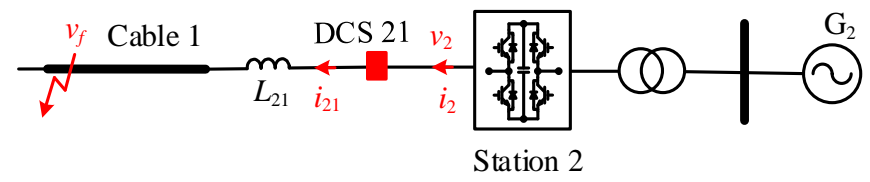

Fig. 2. DC fault protection based on FB-MMCs and DCSs in a radial DC network.

Considering the permanent pole-to-pole DC fault at the middle of Cable 1 as illustrated in Fig. 1, all the three stations are immediately blocked once the DC fault is detected by the respective station based on local measurements [19]. DCCB 12 and 13 are then opened to protect the HB-MMC based Station 1 from overcurrent.

In addition to DCCB 12, DCS 21 also needs to open at around zero current to completely isolate the faulty Cable 1 . Following the blocking of the FB-MMCs (Station 2 and 3), their DC terminal currents, i.e. $i_{2}$ and $i_{3}$ are quickly suppressed to zero, as shown in Fig. 3 (a) for the case of a DC fault at Cable 1 at $0.7 \mathrm{~s}$. Even though DCCB 12 and 13 have opened, significant currents still flow through the DCSs and cables, as the distributed capacitors of the DC cables provide circulating paths for the fault current, as illustrated in Fig. 4. Thus, the current $i_{21}$ flowing through DCS 21 decays slowly, due to the low resistance of the fault current circulating path in Fig. 4. As shown in Fig. 3 (b), it takes over 130 ms for the currents $i_{21}$ to decrease to the range of $\pm 100 \mathrm{~A}$, leading to significant delay for the fault isolation (by opening DCS 21) and the restoration of the healthy part of the system.

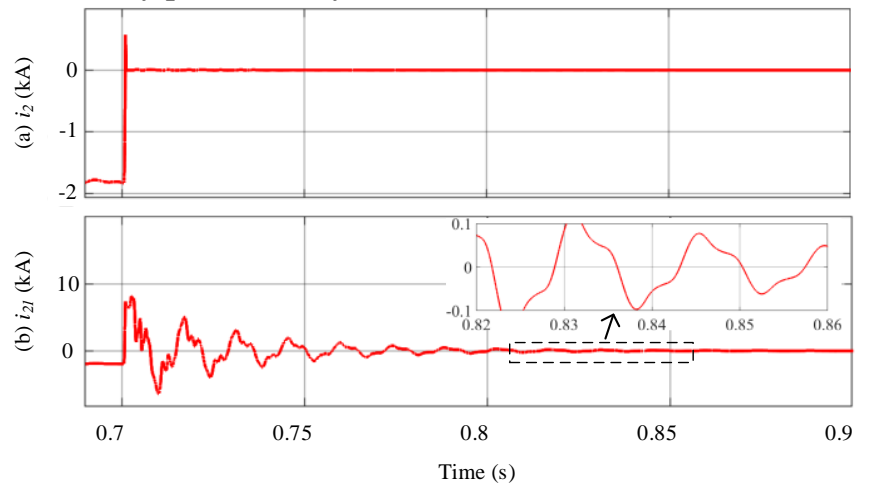

Fig. 3. DC fault currents during the pole-to-pole DC fault applied at Cable 1 in the meshed DC network at $t=0.7 \mathrm{~s}$ : (a) DC current of Station 2 and (b) DC current flowing through DCS 21.

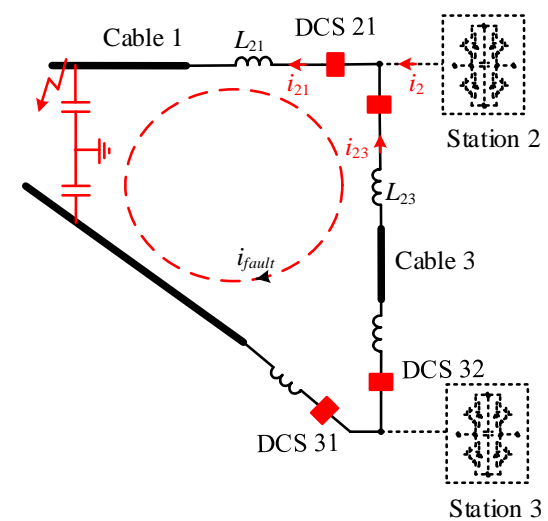

Fig. 4. Illustration of fault current circulating path through distributed capacitors of DC cables.

\section{B. FB-MMC Active Fault Current Control}

Instead of blocking the FB-MMCs during DC faults, active control of the fault current is proposed in [14], where the FBMMC directly controls the fault current flowing through DCS by regulating the DC voltage output of the FB-MMC, as shown in Fig. 5. In this design, the DCS current $i_{21}$ is regulated by a PI controller to adjust the DC voltage $v_{2}$ of the FB-MMC. As shown in Fig. 2, by regulating the voltage difference between $v_{2}$ and the fault voltage $v_{f}$ which is around zero during a low resistance fault, the current $i_{21}$ flowing through the DCS can be quickly suppressed to zero when only one DC cable is connected with the FB-MMC.

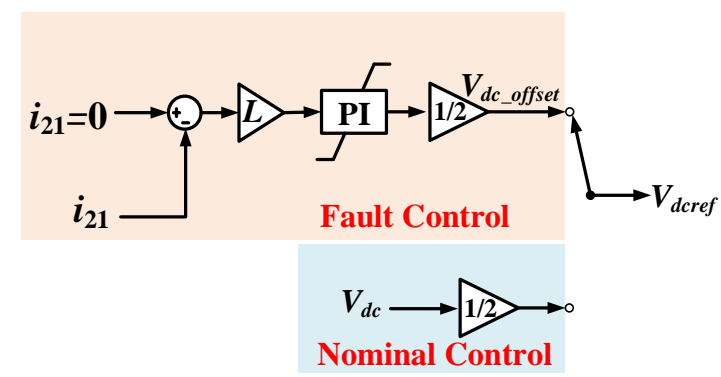

Fig. 5. Control diagram of DC line fault current control. 
When multiple cables are connected at the DC terminal of the FB-MMC, the interaction between the adjacent cables pose a challenge for such control approach. Considered Station 2 of the meshed DC network in Fig. 1 as an example, where both Cable 12 and 23 are connected at the DC terminal of Station 2, the Station 2 FB-MMC tries to suppress the DCS current $i_{21}$ to zero by regulating the output voltage $v_{2}$. However, the regulation of $v_{2}$ also affects the current flowing through Cable 3 in a similar manner as that shown in Fig. 4.

For instance, when the current $i_{21}$ flows to the fault as shown in Fig. 6 (a), the FB-MMC needs to generate a negative voltage $v_{2}$ to suppress $i_{21}$ to 0 . However, the voltage $v_{2}$ shown in Fig. 6 (d) also causes the discharge of Cable 3 and the discharging current $i_{23}$ shown in Fig. 6 (c) potentially flows through DCS 21 and feeds the fault, leading to the increase of the DCS current $i_{21}$.
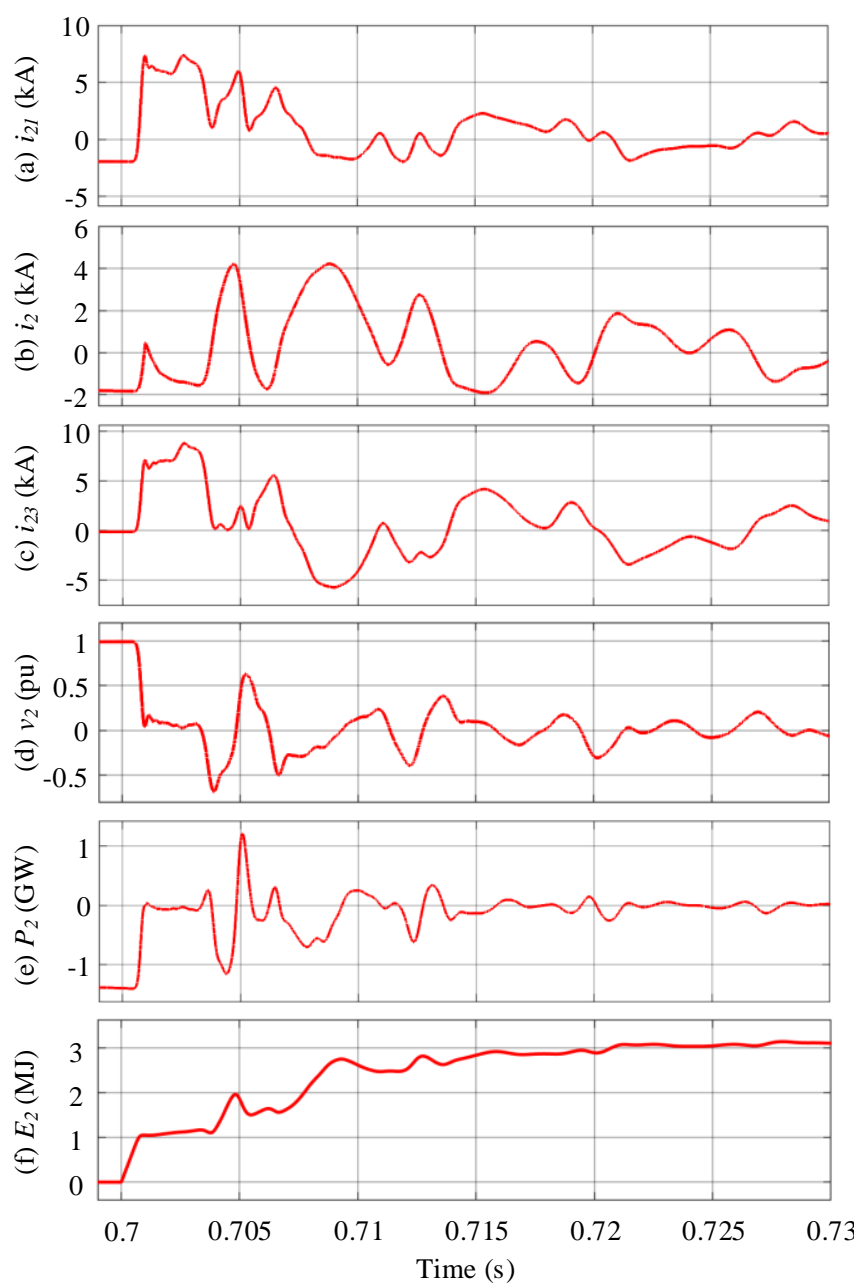

Fig. 6. Waveforms of the hybrid DC network with conventional control, where the DC fault is applied at $t=0.7 \mathrm{~s}$ : (a) DC line current $i_{21}$, (b) DC terminal current $i_{2}$, (c) DC line current $i_{23}$, (d) DC voltage $v_{2}$, (e) active power $P_{2}$ of Station 2 and (f) energy absorbed by Station 2.

The issues related to the above described control interaction can also be explained from the perspective of energy. The active power $P_{2}$ of Station 2 is calculated as

$$
P_{2}=v_{2} i_{2}
$$

and oscillates, as shown in Fig. 6 (e). When $P_{2}$ is negative, Station 2 absorbs energy from the DC network, contributing to the suppression of the DCS current $i_{21}$. However, when $P_{2}$ is positive, Station 2 injects energy from the AC gird to the DC side, leading to the increase of the overall fault currents/energy that circulate in the DC grid. This is also demonstrated by the absorbed energy $E_{2}$ of Station 2 from the DC network, as shown in Fig. 6 (f), which is obtained by integrating the active power $P_{2}$ from $0.7 \mathrm{~s}$ onwards. At the initial stage after the fault occurrence, $E_{2}$ increases and Station 2 absorbs energy from the DC grid but during some periods, it decreases, indicating that Station 2 injects energy back to the DC grid. Consequently, this delays the suppression of the DCS current $i_{21}$, as shown in Fig. 6 (a).

\section{Proposed EnERgy Based Virtual DamPing Control}

\section{A. Control Strategy}

The DC switches can only be opened at around zero current when the DC network is totally de-energized. Thus, from the perspective of energy, the fault isolation speed is heavily determined by speed of de-energization of the DC network by the fault current control algorithm. In the aforementioned conventional control, the FB-MMCs potentially inject energy to the DC network, leading to slow decrease of the fault currents flowing through the DCSs. To tackle this issue, an energy based virtual damping control is proposed in this section.

The basic concept of the propose control is that the FBMMCs are actively controlled during DC faults to absorb energy from the DC network as quickly as possible while avoid injecting energy into the DC network to indirectly suppress the DCS current to zero. As shown in Fig. 7, the proposed control regulates the DC terminal current of the FB-MMC $i_{2}$ instead of directly controlling the DCS current as used in the other methods. This removes the current control issue highlighted in the previous section. The reference $i_{2 r e f}$ is set such that the FBMMC behaves as a DC damping resistor $R_{v}$, i.e. its value is given as:

$$
i_{2 \text { ref }}=\frac{1}{R_{v}} v_{2} .
$$

As the DC terminal voltage $v_{2}$ oscillates around zero during faults, the FB-MMC absorbs DC current from the meshed DC network when $v_{2}$ is positive, and injects current to the DC grid when $v_{2}$ is negative. Thus, the FB-MMC always absorbs energy from the DC network so as to accelerate the de-energization, leading to fast decrease of the DC fault currents circulating in the meshed DC network. Assuming $i_{2}=i_{2 r e f}$ and from (2), the absorbed energy of the FB-MMC is

$$
P_{2}=v_{2} i_{2}=\frac{1}{R_{v}} v_{2}{ }^{2} .
$$

Thus, the virtual DC damping resistor $R_{v}$ emulated by the FBMMC effectively avoids the aforementioned interaction issue between adjacent cables and potential energy injection from the $\mathrm{AC}$ grid to the DC network. Once the DC grid is de-energized by the FB-MMC, the DCS can be open at around zero to isolate the fault. 
As shown in Fig. 7, the DC offset of the arm voltages $v_{\text {uabc }}$ and $v_{l a b c}$ is set at $0.5 V_{d c}$ during normal operation. In the event of a DC fault, the proposed energy based virtual damping control is activated after fault detection to regulate the DC terminal current $i_{2}$ by manipulating the DC offset in the arm voltage, as illustrated in Fig. 7, where $V_{d c_{-} \nu}$ is the output of the proposed virtual damping controller, and $L$ is the equivalent inductance of the FB-MMC and is equal to $L=2 L_{\text {arm }} / 3$ [20,21].

In addition, the conventional method [14] tries to control the DCS current directly which requires accurate fault location to decide which DCS current should be suppressed to zero. This introduces significant delay for the initiation of the fault current control and further leads to slow fault isolation. Also, it is likely that only the FB-MMC connected directly to the faulty cable contributes to the suppression of the fault current flowing through the DCS.

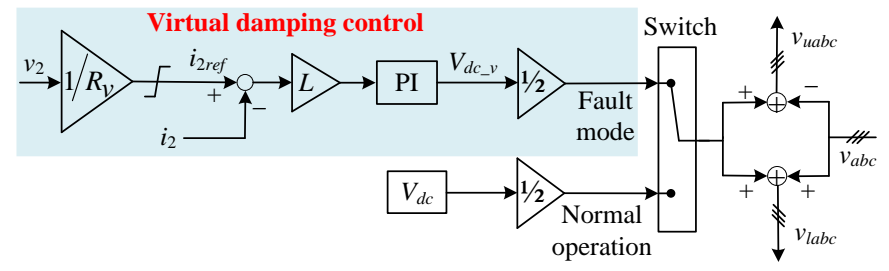

Fig. 7. Proposed energy based virtual damping control.

In contrast, the proposed virtual damping control does not rely on the information of fault location and can be immediately initiated once the DC fault is detected by the FB-MMC based on local measurements. In addition, all the FB-MMCs automatically absorb residual energy from the DC network with the proposed control, yielding faster de-energization and fault isolation.

Fig. 8 compares the DC current $i_{21}$ flowing through DCS 21 with the conventional control and the proposed virtual damping control. The time when $i_{21}$ is controlled into the range of \pm 100 A is significantly reduced from over $50 \mathrm{~ms}$ to less than $15 \mathrm{~ms}$ by the proposed control. Thus, DCS 21 can be opened within $15 \mathrm{~ms}$ after fault initiation, leading to fast fault isolation as shown in Fig. 8, where $t_{D C C B}$ represents the opening time of DCCB 12 and 13, and $t_{D C S 1}$ and $t_{D C S 2}$ indicate the opening time of DCS 21 with the proposed control and the conventional control, respectively.

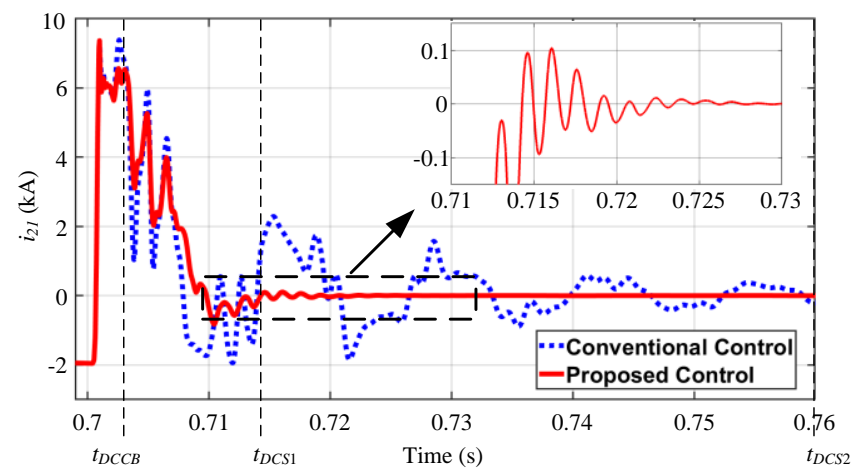

Fig. 8. Comparison of the DCS 21 currents $i_{21}$ with conventional control and proposed control.
In addition to FB-MMCs, the proposed control is also applicable for other alternatives with negative voltage generating capability, e.g. hybrid MMCs [22], cross-connected SM based MMCs [23, 24], etc.

\section{B. Influence of the Virtual Damping Resistance $R_{v}$}

The FB-MMC with the proposed control is equivalent to a virtual resistor $R_{v}$ connected with a voltage source $v_{2}$ and its absorbed power is depicted by (3). Thus, with lower virtual resistance $R_{v}$, the FB-MMC can absorb the residual power of the DC grid quicker, yielding faster fault current suppression, as demonstrated in Fig. 9 (a). However, lower virtual resistance $R_{v}$ incurs large DC current $i_{2}$ as depicted by (2) and shown in Fig. 9 (b) which has to be handled by the FB-MMC. Therefore, the tradeoff between performance and converter current stress must be considered carefully when tuning the virtual resistance.

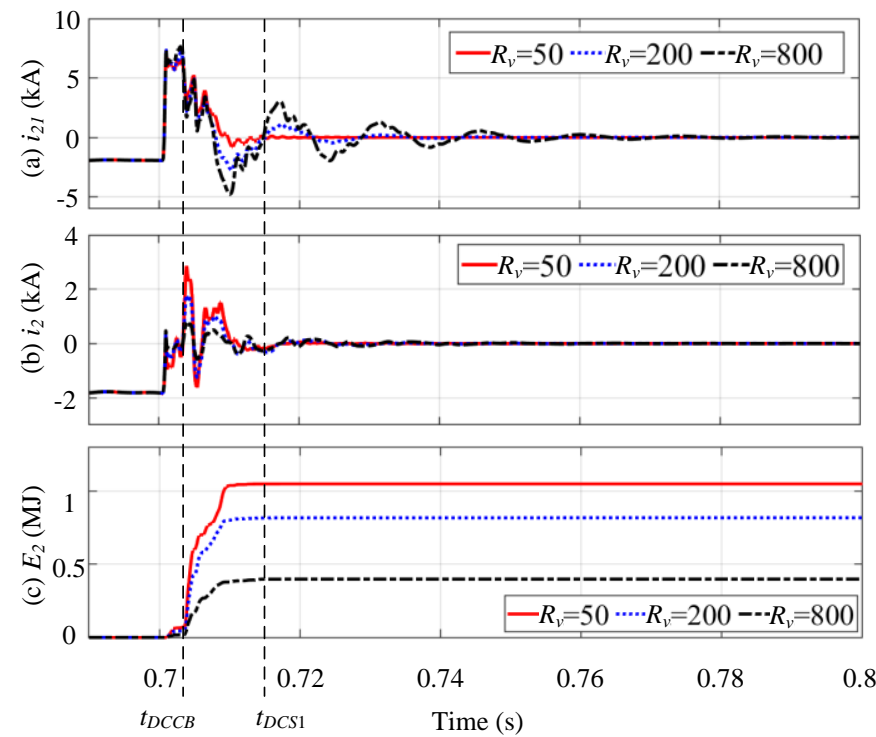

Fig. 9. Influence of the virtual damping resistance $R_{v}$ on the proposed control: (a) current flowing through DCS 21, (b) DC terminal current of Station 2 and (c) energy absorbed by Station 2 .

To avoid overcurrent, a saturation block is used to limit the DC terminal current reference $i_{2 r e f}$ at 1.4 pu as shown in Fig. 7. For higher current limit, e.g. 2 pu, the FB-MMC is allowed to generate larger DC terminal current and thus can potentially absorb the residual energy from the DC network quicker, leading to faster de-energization and fault isolation. Considering the tradeoff between system performance and converter current stress, the limit of the DC terminal current reference is set at 1.4 pu in this paper. As seen in Fig. 9 (b), the maximum DC current is limited to $2.7 \mathrm{kA}$ (1.4 pu).

Fig. 9 (c) displays the energy absorbed by Station 2 with different virtual damping resistance $R_{v}$. The absorbed energy of Station 3 exhibits similar behavior to that of Station 2 and is not presented. With lower virtual resistance $R_{v}$, the FB-MMC absorbs the residual energy from the DC grid quicker for fast de-energization, which is in agreement with Fig. 9 (a). When higher $R_{v}$ is used, it takes longer to suppress the circulating current through the DC network and thus, more energy is dissipated by the DC cable resistors and less needs to be absorbed by the FB-MMCs. Consequently, as observed in Fig. 
9 (c), the energy absorbed by the FB-MMCs with $R_{v}=800 \Omega$ is slightly lower than that with $R_{v}=50 \Omega$, considering constant residual energy of the DC network that needs to be dissipated by either DC cables or FB-MMCs. However, as the DC terminal current is limited at $1.4 \mathrm{pu}, R_{v}$ value less than $50 \Omega$ simply leads to current limit and thus no further improvement on the control performance can be achieved. Virtual damping resistance $R_{v}$ is thus set at $50 \Omega$ for both Station 2 and 3 .

\section{Simulation Results}

To assess the effectiveness of the proposed virtual damping control, a permanent pole-to-pole DC short circuit fault is applied at the middle of Cable 1 at $t=0.7 \mathrm{~s}$, as illustrated in Fig. 1. The faulty DC line is isolated using a combination of DCCB
12 and DCS 21 with the assistance of FB-MMC Stations 2 and 3, as follows:

- After fault detection [19], HB-MMC based Station 1 is blocked while DCCB 12 and 13 open within $5 \mathrm{~ms}$ to break the fault current.

- FB-MMC based Station 2 and 3 remain operational with the proposed virtual damping control to quickly suppress the DC fault current.

- When the DC current flowing through DCS 21 is reduced within $\pm 100 \mathrm{~A}$, DCS 21 is opened for fault isolation.

After isolation of the faulty Cable 1, the system resumes power transmission through Cable 2 and 3. The system performances during fault clearance and recovery are addressed in the following subsections A and B, respectively.
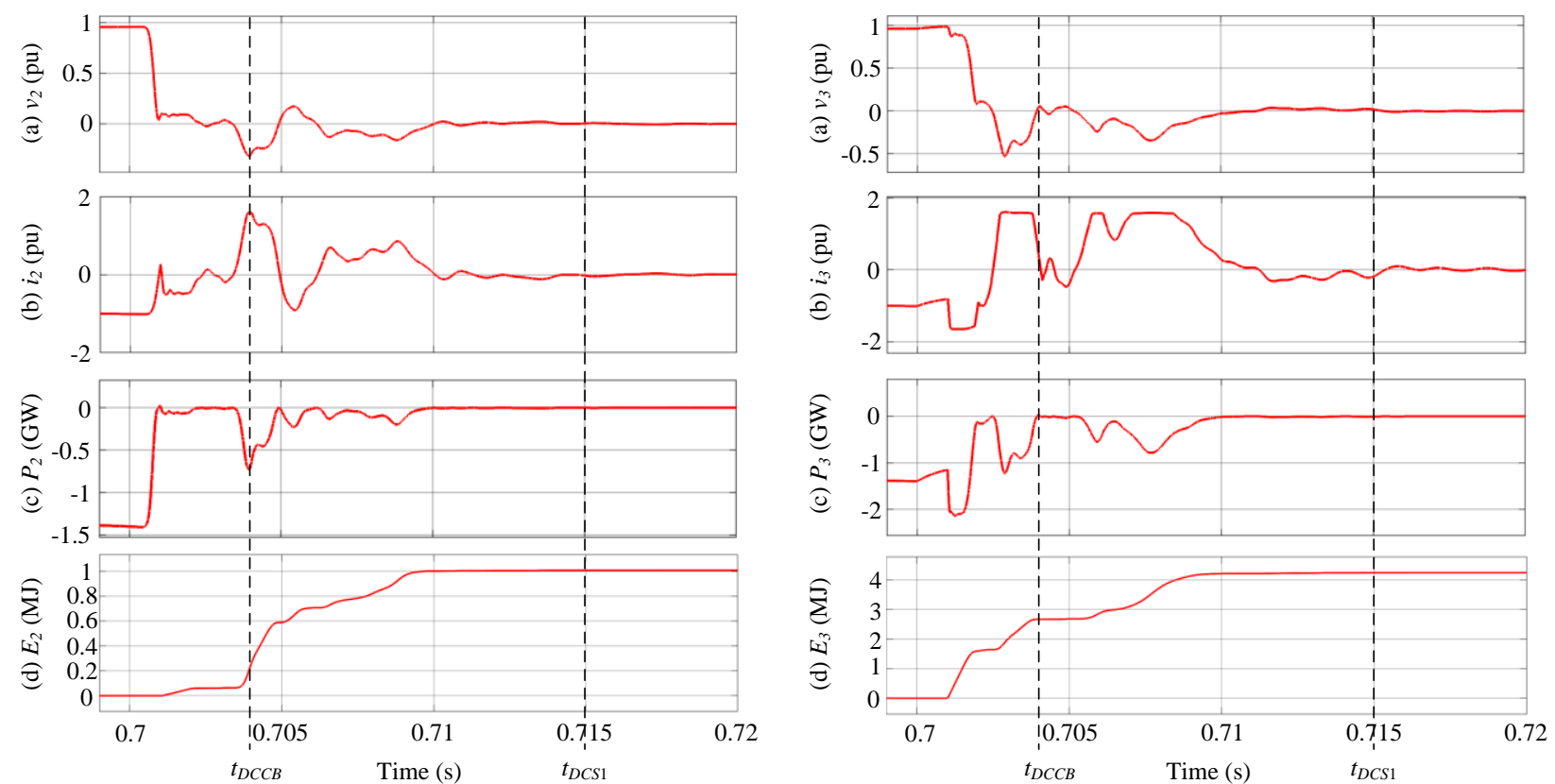

Fig. 10. Waveforms of (i) Station 2 and (ii) Station 3 during fault clearance: (a) DC voltage, (b) DC current, (c) DC power and (d) energy absorbed by FBMMC.
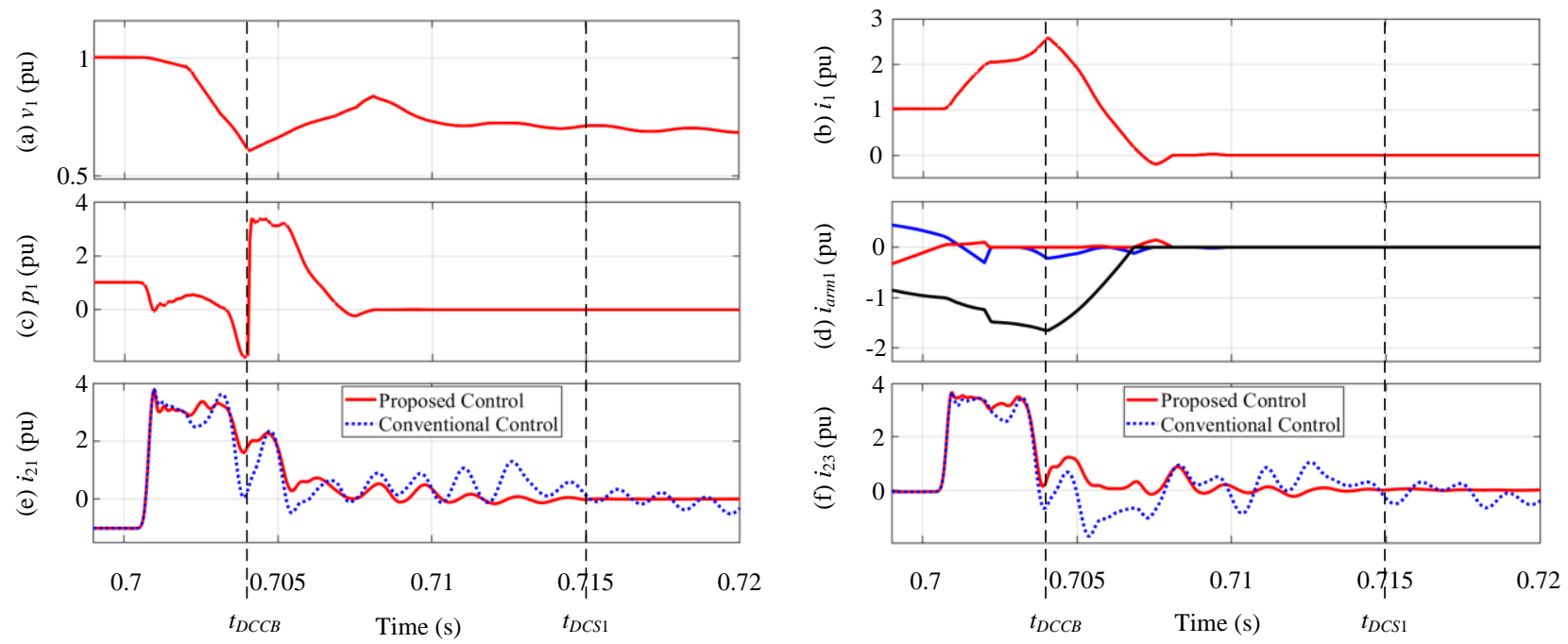

Fig. 11. Waveforms of Station 1 and DCSs during fault clearance under the proposed and conventional controls: (a) DC voltage of Station 1, (b) DC current of Station 1, (c) active power of Station 1, (d) arm currents of Station 1, (e) DC current of DCS 21 and (f) DC current of DCS 23. 


\section{A. Fault Clearance Using DCSs and FB-MMCs with the Proposed Virtual Damping Control}

Simulated waveforms for Station 2 and 3 are shown in Fig. 10, while Fig. 11 shows the results of Station 1 and the currents flowing through the DCSs. In Fig. 11 (e) and (f), the currents of DCS 21 and 23 using the proposed method and the conventional control [14] are compared.

After the DC fault occurrence at $t=0.7 \mathrm{~s}$, the DC voltage of the DC grid collapses, as shown in Fig. 10 (a). Station 1 detects the fault at $t=0.702 \mathrm{~s}$ and is blocked immediately. Large fault currents flow through the antiparallel diodes of Station 1 to the fault. DCCB 12 and 13 at the DC terminal of Station 1 open at $t_{D C C B}=0.704 \mathrm{~s}$ to break the fault current from Station 1, as displayed in Fig. 11 (b) and (d) for the DC current and arm currents of Station 1.

The FB-MMC based Station 2 and 3 detect the fault at $t=0.701 \mathrm{~s}$ and $0.702 \mathrm{~s}$ respectively and switch to the proposed virtual damping control mode. The DC terminal currents $i_{2}$ and $i_{3}$ are controlled to follow the DC terminal voltages $v_{2}$ and $v_{3}$, as can be seen in Fig. 10 (a) and (b) where $i_{2}$ and $i_{3}$ exhibit similar shape (the DC current is limited to $1.4 \mathrm{pu}$ of the respective rated converter current as previously described) to those of $v_{2}$ and $v_{3}$ in the virtual damping control mode. Thus, the power $P_{2}$ and $P_{3}$ of Station 2 and 3 are always negative and the FB-MMC stations only absorb energy from DC grid as displayed in Fig. 10 (c). The issue of potentially re-injecting

(i) Station 2

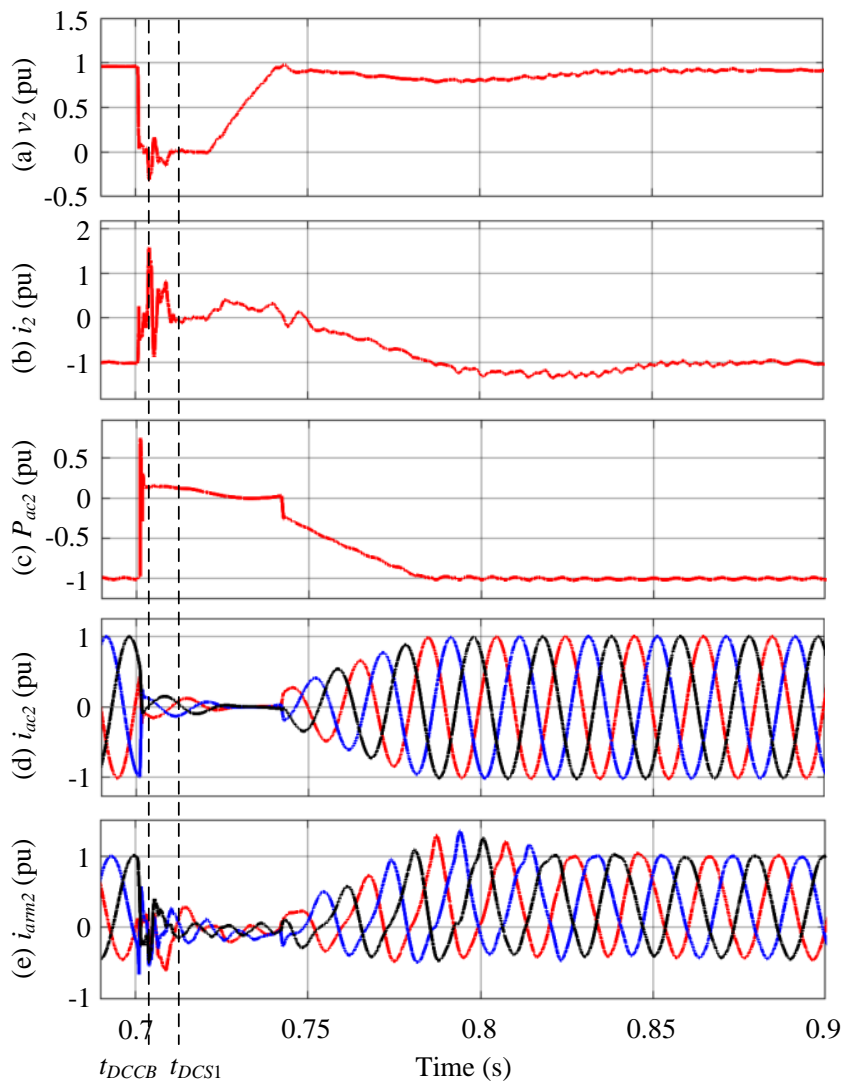

power from AC gird to the DC network shown in Fig. 6 is effectively avoided. This is also demonstrated by the energies absorbed by the FB-MMCs as shown Fig. 10 (d), which keep increasing until the system is completely de-energized.

The circulating fault currents that flow through the DCSs, DC cables and their distributed capacitors are quickly suppressed to zero, as shown in Fig. 11 (e) and (f). Then DCS 21 is opened at around zero currents at $t_{D C S 1}=0.715 \mathrm{~s}$ for fault isolation after the fault is located at Cable 1. In comparison, the conventional control needs longer time to suppress the DC fault currents flowing through DCS 21 and 23, leading to slow fault isolation, as observed in Fig. 11 (e) and (f). As DCCB 12 and 13 open at $t=t_{D C C B}$ for both the control methods, the DC voltage, DC current, active power and arm currents of Station 1 with conventional control are similar to those with the proposed control shown in Fig. 11 (a)-(d) and thus are not presented.

As Station 3 is adjacent to the longest Cable 2, its absorbed energy is greater than that of Station 2, as seen in Fig. 10 (d). The DC current of Station 3 is limited within 1.4 pu to avoid converter overcurrent while the Station 2 DC current remains below the limit of $1.4 \mathrm{pu}$, as observed in Fig. 10 (b).

With the proposed control, the FB-MMCs act as damping resistors and absorb energy from the DC network to accelerate its de-energization in the event of a DC fault, leading to quick suppression of the DCS currents and thereby fast fault isolation.

\section{B. System Recovery}

(ii) Station 3
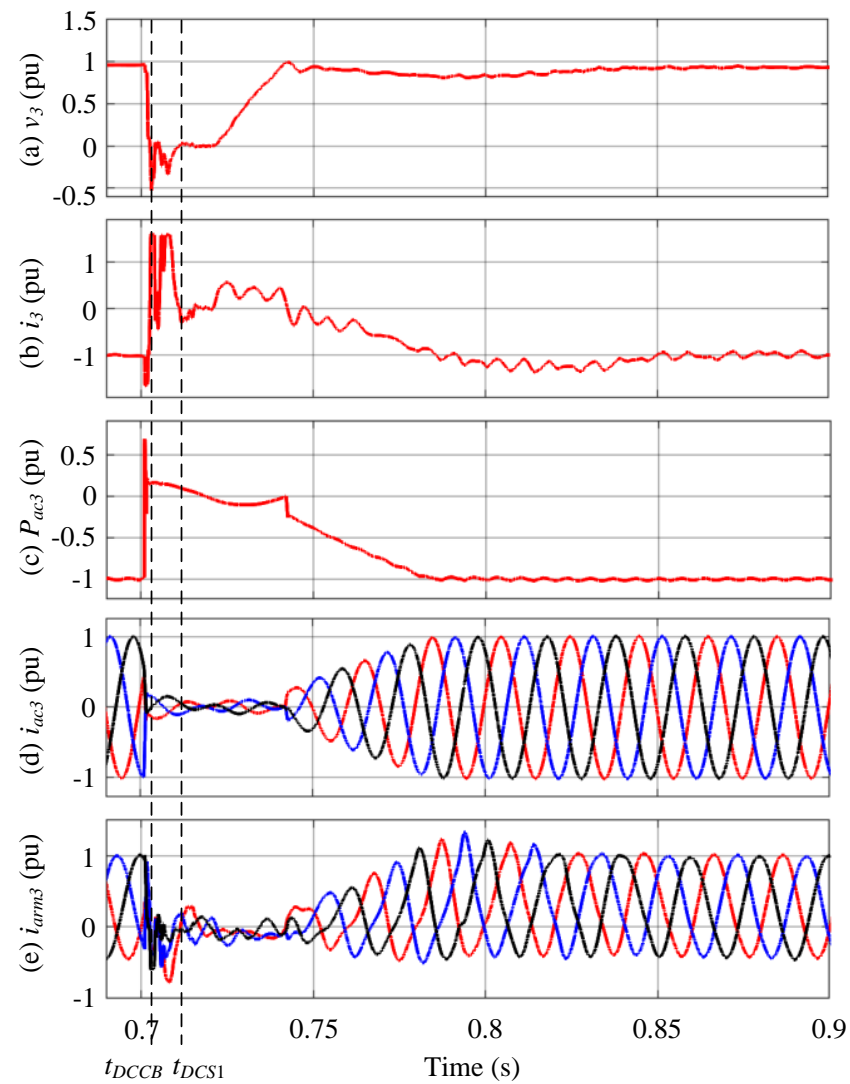

Fig. 12. Waveforms of (i) Station 2 and (ii) Station 3 during system recovery: (a) DC voltage, (b) DC current, (c) active power, (d) AC currents and (e) arm currents. 

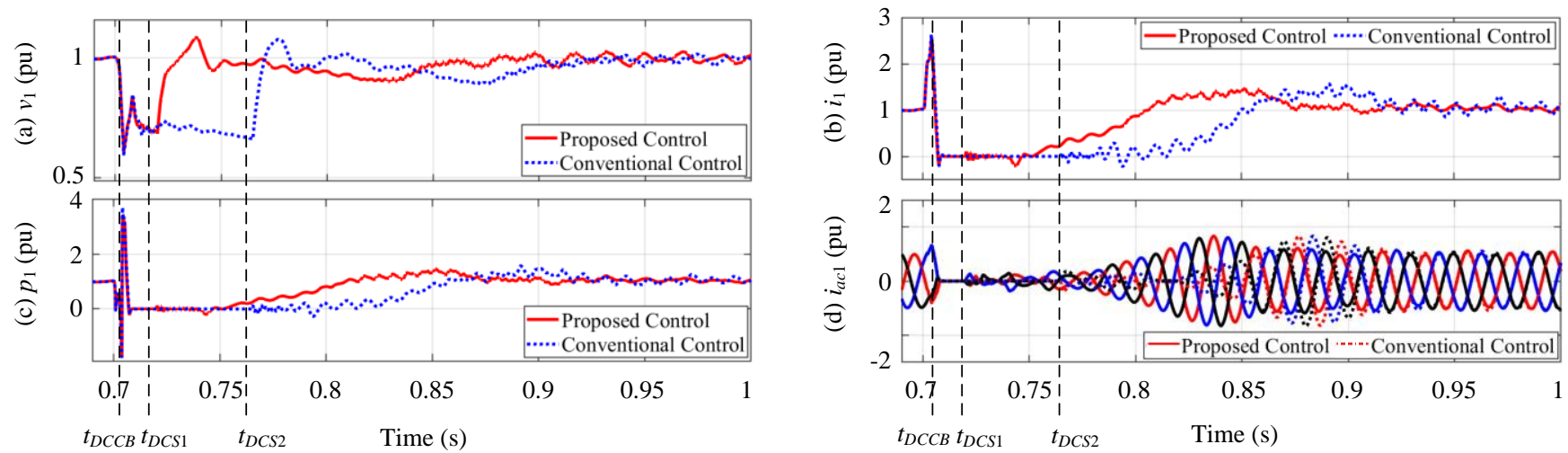

Fig. 13. Waveforms of Station 1 during system recovery under the proposed and conventional controls: (a) DC voltage, (b) DC current, (c) active power and (d) AC currents.

The complete protection and recovery process using the proposed virtual damping control is shown in Fig. 12 and Fig. 13. After isolation of the faulty Cable 1 from the DC network as described in the above subsection, the FB-MMC based Station 2 and 3 switch to DC voltage control mode at $t=0.72 \mathrm{~s}$ to charge Cable 2 and 3 and ramp the DC voltage to the rated value in $20 \mathrm{~ms}$, as seen in Fig. 12 (a). The HB-MMC at Station 1 is de-blocked $t=0.725 \mathrm{~s}$ to restore its terminal voltage to the nominal value, as shown in Fig. 13 (a). When the DC voltage across DCCB 13 is close to $1 \mathrm{pu}$, it is reclosed at $t=0.74 \mathrm{~s}$, reconnecting Station 1 to the DC grid. During the DCCB 13 reclosing process, the DC grid voltages and currents do not see disturbance as shown in Fig. 12 (a) and (b). Station 1 takes control of the DC voltage of the DC grid, and Station 2 and 3 subsequently switch back to active power control mode and ramp up the active power to the rated value in $60 \mathrm{~ms}$, as shown in Fig. 12 (c) and Fig. 13 (c).

During the DC fault and DC grid restoration, the AC and arm currents of the stations remain well regulated without significant overshoots, as demonstrated in Fig. 12 (d) and (e). The fault isolation time that the proposed DC fault ride-through scheme offers in this illustration is around $15 \mathrm{~ms}$ (i.e. $t_{D C S 1}=0.715 \mathrm{~s}$ ), much shorter than those from other methods, e.g., FB-MMC blocked (120 ms), control of common-mode components of arm currents (75 ms) [9, 10], and conventional fault current control ( $50 \mathrm{~ms}$, i.e. $t_{D C S 2}=0.75 \mathrm{~s}$ ) [14], as listed in Table II. Thus, the system can quickly recover with the proposed control, as compared in Fig. 13.

TABLE II

COMPARISON OF FAULT ISOLATION TIME WITH DiFFERENT METHODS

\begin{tabular}{l|c}
\hline \multicolumn{1}{c|}{ Control Methods } & Fault Isolation Time \\
\hline Proposed control & $15 \mathrm{~ms}$ \\
\hline Conventional fault current control [14] & $50 \mathrm{~ms}$ \\
\hline $\begin{array}{l}\text { Control of common-mode components of } \\
\text { arm currents [9,10] }\end{array}$ & $75 \mathrm{~ms}$ \\
\hline All converters blocked & $120 \mathrm{~ms}$ \\
\hline \hline
\end{tabular}

\section{CONCLUSION}

Conventional active fault current control of FB-MMC during DC faults aims to directly suppress the DC current in the faulty cable for fast fault isolation using DC switches. However, for meshed DC grid, due to the coupling and interconnection of the DC cables, such method may lead to energy injection by the FB-MMC to the DC network which deteriorates the fault current suppression during DC faults. A new energy based virtual damping control for FB-MMC is proposed to fast suppress the fault current that circulates within the meshed MTDC system. In the proposed control, the terminal current of the FB-MMC is controlled to follow the terminal voltage during DC faults to act as a virtual resistor to quickly absorb the residual energy from the DC network, thus the issue of conventional active fault current control is effectively avoided. The operating mechanism of the proposed control is revealed from the energy perspective and the design principle of the virtual resistance is discussed. The simulation results in a threeterminal meshed DC system demonstrate that the fault isolation time is significantly reduced from around $50 \mathrm{~ms}$ to $15 \mathrm{~ms}$ compared to conventional active fault current control, alleviating interruption of power transmission during DC faults.

\section{REFERENCES}

[1] M. B. Ghat and A. Shukla, "A New H-Bridge Hybrid Modular Converter (HBHMC) for HVDC Application: Operating Modes, Control, and Voltage Balancing," IEEE Transactions on Power Electronics, vol. 33, no. 8, pp. 6537-6554, 2018.

[2] T. H. Nguyen, K. H. A. Hosani, and M. E. Moursi, "Alternating Submodule Configuration Based MMCs with Carrier-Phase-Shift Modulation in HVDC Systems for DC-Fault Ride-Through Capability," IEEE Transactions on Industrial Informatics, pp. 1-1, 2019.

[3] X. Chen, L. Wang, H. Sun, and Y. Chen, "Fuzzy Logic Based Adaptive Droop Control in Multiterminal HVDC for Wind Power Integration," IEEE Transactions on Energy Conversion, vol. 32, no. 3, pp. 1200-1208, 2017.

[4] X. Jianzhong, Z. Chengyong, H. Zhipeng, and G. Yuqun, "Start-up control and DC fault ride-through strategies of a hybrid MMC-HVDC system suitable for overhead line transmission," in 2015 IEEE 2nd International Future Energy Electronics Conference (IFEEC), 2015, pp. 1-6.

[5] M. Fawzi, F. Briz, and A. E. Kalas, "DC short circuit ride-through strategy for a full-bridge MMC HVDC transmission system," in 2017 19th European Conference on Power Electronics and Applications (EPE'17 ECCE Europe), 2017, pp. P.1-P.10.

[6] SIEMENS, "The energy transition in Germany - Siemens supplies converters for grid expansion to Amprion and TransnetBW," pp. 1-48, 2016.

[7] Y. Luo, P. Yi, X. Xiaofu, W. Jiang, and S. Yonghui, "DC fault ridethrough method for full-bridge MMC-based MTDC systems," The Journal of Engineering, vol. 2019, no. 16, pp. 3175-3179, 2019. 
[8] R. Li, L. Yu, L. Xu, and G. P. Adam, "DC Fault Protection of Diode Rectifier Unit Based HVDC System Connecting Offshore Wind Farms," in 2018 IEEE Power \& Energy Society General Meeting (PESGM), 2018, pp. 1-5.

[9] G. P. Adam and I. E. Davidson, "Robust and Generic Control of FullBridge Modular Multilevel Converter High-Voltage DC Transmission Systems," IEEE Transactions on Power Delivery, vol. 30, no. 6, pp. 2468-2476, 2015.

[10] C. Chen, G. P. Adam, S. Finney, J. Fletcher, and B. Williams, "H-bridge modular multi-level converter: control strategy for improved DC fault ride-through capability without converter blocking," IET Power Electronics, vol. 8, no. 10, pp. 1996-2008, 2015.

[11] W. Xiang, W. Lin, L. Xu, and J. Wen, "Enhanced Independent Pole Control of Hybrid MMC-HVdc System," IEEE Transactions on Power Delivery, vol. 33, no. 2, pp. 861-872, 2018.

[12] J. Hu, Z. He, L. Lin, K. Xu, and Y. Qiu, "Voltage Polarity ReversingBased DC Short Circuit FRT Strategy for Symmetrical Bipolar FBSMMMC HVDC System," IEEE Journal of Emerging and Selected Topics in Power Electronics, vol. 6, no. 3, pp. 1008-1020, 2018.

[13] D. Jovcic, W. Lin, S. Nguefeu, and H. Saad, "Low-Energy Protection System for DC Grids Based on Full-Bridge MMC Converters," IEEE Transactions on Power Delivery, vol. 33, no. 4, pp. 1934-1943, 2018.

[14] P. Ruffing, N. Collath, C. Brantl, and A. Schnettler, "DC Fault Control and High-Speed Switch Design for an HVDC Network Protection Based on Fault-Blocking Converters," IEEE Transactions on Power Delivery, vol. 34, no. 1, pp. 397-406, 2019.

[15] P. Ruffing, C. Brantl, C. Petino, and A. Schnettler, "Fault current control methods for multi-terminal DC systems based on fault blocking converters," The Journal of Engineering, vol. 2018, no. 15, pp. 871-875, 2018.

[16] R. Li, L. Xu, L. Yao, and B. W. Williams, "Active Control of DC Fault Currents in DC Solid-State Transformers During Ride-Through Operation of Multi-Terminal HVDC Systems," IEEE Transactions on Energy Conversion, vol. 31, no. 4, pp. 1336-1346, 2016.

[17] W. Wen et al., "Research on a current commutation drive circuit for hybrid dc circuit breaker and its optimisation design," IET Generation, Transmission \& Distribution, vol. 10, no. 13, pp. 3119-3126, 2016.

[18] L. v. d. S. René Smeets, Mirsad Kapetanovic, David F. Peelo, Anton Janssen, Switching in Electrical Transmission and Distribution Systems. Wiley, 2014.

[19] R. Li, L. Xu, and L. Yao, "DC Fault Detection and Location in Meshed Multiterminal HVDC Systems Based on DC Reactor Voltage Change Rate," IEEE Transactions on Power Delivery, vol. 32, no. 3, pp. 1516$1526,2017$.

[20] R. Li, L. Xu, D. Holliday, F. Page, S. J. Finney, and B. W. Williams, "Continuous Operation of Radial Multiterminal HVDC Systems Under DC Fault," IEEE Transactions on Power Delivery, vol. 31, no. 1, pp. 351-361, 2016.

[21] J. Qin, M. Saeedifard, A. Rockhill, and R. Zhou, "Hybrid Design of Modular Multilevel Converters for HVDC Systems Based on Various Submodule Circuits," IEEE Transactions on Power Delivery, vol. 30, no. 1, pp. 385-394, 2015.

[22] R. Zeng, L. Xu, L. Yao, and B. W. Williams, "Design and Operation of a Hybrid Modular Multilevel Converter," Power Electronics, IEEE Transactions on, vol. 30, no. 3, pp. 1137-1146, 2015.

[23] S. Debnath, Q. Jiangchao, B. Bahrani, M. Saeedifard, and P. Barbosa, "Operation, Control, and Applications of the Modular Multilevel Converter: A Review," Power Electronics, IEEE Transactions on, vol. 30, no. 1, pp. 37-53, 2015.

[24] A. Nami, L. Jiaqi, F. Dijkhuizen, and G. D. Demetriades, "Modular Multilevel Converters for HVDC Applications: Review on Converter Cells and Functionalities," Power Electronics, IEEE Transactions on, vol. 30, no. 1, pp. 18-36, 2015.

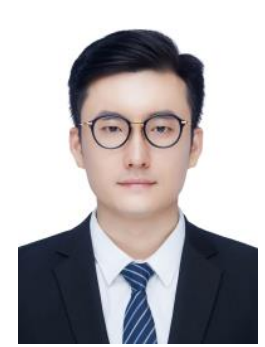

Ding Zhou received the M.Sc. and Ph.D. degrees both in electronic and electrical engineering from University of Strathclyde, Glasgow, U.K., in 2014 and 2020 respectively.

Currently, he is working with Global Energy Interconnection Research Institute Co., Ltd., Beijing, China. His research interests include power electronics, DC networks protection and application of power electronics to power systems.

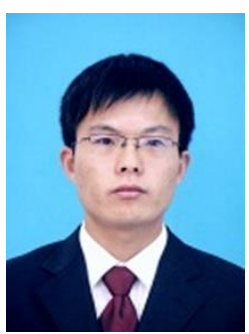

Rui Li (M'18) received the M.S. and Ph.D degrees in electrical engineering from Harbin Institute of Technology, Harbin, China, in 2008 and 2013, respectively. $\mathrm{He}$ is a researcher with University of Strathclyde in Glasgow, UK, since 2013.

His research interests include HVDC transmision systems, grid integration of renewable power, power electronic converters, and energy conversion.

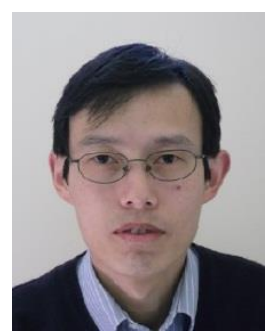

Lie Xu (M'03-SM'06) received the B.Sc. degree in Mechatronics from Zhejiang University, Hangzhou, China, in 1993, and the Ph.D. degree in Electrical Engineering from the University of Sheffield, Sheffield, UK, in 2000.

He is currently a Professor at the Department of Electronic \& Electrical Engineering, University of Strathclyde, Glasgow, UK. He previously worked in Queen's University of Belfast and ALSTOM T\&D, Stafford, UK. His current research interests include power electronics, wind energy generation and grid integration, and application of power electronics to power systems. He is an Editor of IEEE Transactions on Power Delivery and IEEE Transactions on Energy Conversion.

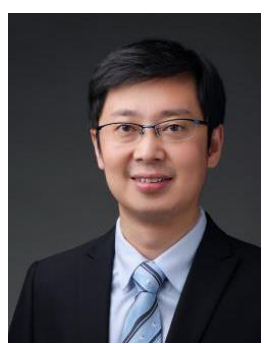

Yi Wang received the B.Sc. and Ph. D degrees in Electrical Engineering from North China Electric Power University, China, in 1999 and 2005, respectively. He is currently a Professor in the School of Electrical and Electronic Engineering, North China Electric Power University. His research interests include the control of wind power integration and DC grids. 